

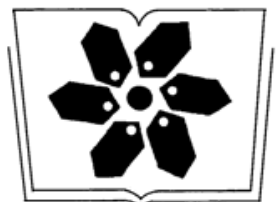

中国科学院科学出版基金资助出版
生 态 学 报

(SHENGTAI XUEBAO)

第 33 卷第 19 期 2013 年 10 月 (半月刊)

中国生态学学会 2013 年学术年会专辑 卷首语

生态系统服务研究文献现状及不同研究方向评述。 马凤娇, 刘金铜, A. Egrinya Eneji (5963) 非人灵长类性打摚行为研究进展 杨斌,王程亮,纪维红,等 (5973) 密度制约效应对啮齿动物繁殖的影响 . 韩群花, 郭 聪, 张美文 (5981) 食物链长度远因与近因研究进展综述 王玉玉,徐军,雷光春 (5990) $\mathrm{AM}$ 真菌在植物病虫害生物防治中的作用机制 罗巧玉，王晓娟，李媛媛，等 (5997) 保护性耕作对农田碳、氮效应的影响研究进展 . 薛建福, 赵 荃金, Shadrack Batsile Dikgwatlhe, 等 (6006) 圈养大熊猫野化培训期的生境选择特征 张明春,黄炎,李德生,等 (6014) 利用红外照相技术分析野生白冠长尾雉活动节律及时间分配 赵玉泽, 王志臣,徐基良,等 (6021) 风速和持续时间对树麻雀能量收支的影响 杨志宏, 吴庆明, 董海燕, 等 (6028) 白马雪山自然保护区灰头小舀鼠的巢址特征 李艳红, 关进科,黎大勇,等 (6035) 生境片段化对千岛湖岛屿上黄足厚结猛蚁遗传多样性的影响 罗媛媛, 刘金亮, 黄杰灵, 等 (6041) 基于 $28 \mathrm{~S}$, COI 和 Cytb 基因序列的薜荔和爱玉子传粉小蜂分子遗传关系研究

吴文珊, 陈友铃, 孙伶俐, 等 (6049) 高榕榕果内 Eupristina 属两种榕小蜂的遗传进化关系 陈友铃, 孙伶例, 武蕾蕾, 等 $(6058)$ 镉胁迫下杞柳对金属元素的吸收及其根系形态构型特征 王树风, 施翔, 孙海菁, 等 (6065) 邻苯二甲酸对萝卜种子萌发、幼苗叶片膜脂过氧化及渗透调节物质的影响

杨延杰, 王晓伟, 赵 康, 等 (6074)

极端干旱区多枝柽柳幼苗对人工水分干扰的形态及生理响应 马晓东, 王明慧, 李卫红, 等 (6081) 贝壳砂生境酸柬叶片光合生理参数的水分响应特征..... 王荣荣,夏江宝,杨吉华,等 (6088) 陶粒覆盖对土壤水分、植物光合作用及生长状况的影响..... 谭雪红, 郭小平, 赵廷宁 (6097) 不同林龄短枝木麻黄小枝单宁含量及养分再吸收动态..... 叶功富, 张尚炬, 张立华,等 (6107)

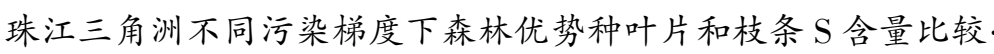
裴男才, 陈步峰, 邹志谨, 等 (6114) $\mathrm{AM}$ 真菌和磷对小马安羊蹄甲幼苗生长的影响 宋成军,曲来叶,马克明, 等 (6121) 盐氮处理下盐地碱蓬种子成熟过程中的离子积累和种子萌发特性............... 周家超,付婷婷, 赵维维,等 (6129) $\mathrm{CO}_{2}$ 浓度升高条件下内生真菌感染对宿主植物的生理生态影响 师志冰, 周 勇, 李 夏, 等 $(6135)$ 预处理方式对香蒲和芦苇种子萌发的影响 孟 焕,王雪宏,佟守正,等 (6142) 镉在土壤-金丝垂柳系统中的迁移特征 雯, 魏 虹, 孙晓灿, 等 (6147) 马尾松人工林近自然化改造对植物自然更新及物种多样性的影响........ 罗应华,孙冬婧,林建勇,等 (6154) 濒危海草贝克喜盐草的种群动态及土壤种子库 以广西珍珠湾为例……

邱广龙,范航清,李宗善,等 (6163)

毛乌素沙地南缘沙丘生物结皮对凝结水形成和蒸发的影响 尹瑞平, 吴永胜, 张 欣, 等 (6173) 塔里木河上游灰胡杨种群生活史特征与空间分布格局…… 韩 路, 席琳乔, 王家强, 等 (6181)

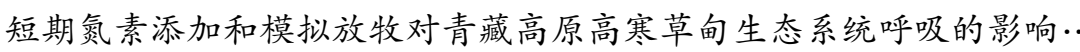
宗宁, 石培礼, 蔣 婧, 等 (6191) 松嫩平原微地形下土壤水盐与植物群落分布的关系 杨 帆,王志春,王云贺,等 (6202) 
广州大夫山雨季林内外空气 TSP 和 $\mathrm{PM}_{2.5}$ 浓度及水溶性离子特征 马鞍列岛岩礁生境鱼类群落结构时空格局…… 黄海细纹狮子鱼种群特征的年际变化. 三种温带森林大型土壤动物群落结构的时空动态 笔管榕榕小蜂的群落结构与物种多样性 海洋生态资本理论框架下的生态系统服务评估 中国地貌区划系统一以自然保护区体系建设为目标..... 生态植被建设对黄土高原农林复合流域景观格局的影响 华北农牧交错带农田-草地景观镶嵌体土壤水分空间异质性 中国北方春小麦生育期变化的区域差异性与气候适应性 中国南方喀斯特石漠化演替过程中土壤理化性质的响应 气候变化对东北沼泽湿地潜在分布的影响…… 内蒙古不同类型草地土壤氮矿化及其温度敏感性 黑河中游荒漠绿洲区土地利用的土壤养分效应 成都平原北部水稻土重金属含量状况及其潜在生态风险评价 大西洋中部延绳钓黄鯺金枪鱼渔场时空分布与温跃层的关系

夏季台湾海峡南部海域上层水体的生物固氮作用 北长山岛森林乔木层碳储量及其影响因子

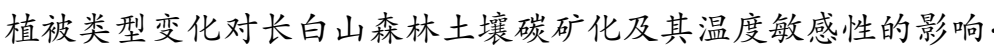
油松遗传结构与地理阻隔因素的相关性 ... 基于辅助环境变量的土壤有机碳空间插值 以黄土丘陵区小流域为例
肖以华, 李昫, 旷远文, 等 (6209) 汪振华, 赵 静, 王 凯, 等 (6218) 陈云龙, 单秀娟, 周志鹏, 等 (6227) . 李 娜, 张雪萍, 张利敏 (6236) 陈友铃, 陈晓倩, 吴文珊, 等 (6246) 陈 尚, 任大川, 夏 涛, 等 (6254) . 郭子良, 崔国发( 6264) 易扬, 信忠保, 覃云斌, 等 (6277) 王红梅, 王仲良, 王 壁, 等 (6287) 俄有浩, 霍治国, 马玉平, 等 (6295) ... 盛茂银, 刘洋, 熊康宁 (6303) 贺伟, 布仁仓, 刘宏娟, 等 (6314) 朱剑兴, 王秋风, 何念鹏, 等 (6320) 马志敏, 吕一河, 孙飞翔, 等 (6328) 秦鱼生, 喻华, 冯文强, 等 (6335) 杨胜龙, 马军杰, 张禹, 等 (6345) 林 峰, 陈 敏, 杨伟锋, 等 (6354) 石洪华, 王晓丽, 王 嫒, 等 (6363) 王丹, 吕瑜良, 徐 丽, 等 (6373) 孟翔翔, 狄晓艳, 王孟本, 等 (6382)

文 雯, 周宝同, 汪亚峰, 等 (6389)

基于生命周期视角的产业资源生态管理效益分析一以虚拟共生网络系统为例

施晓清,李笑诺,杨建新 (6398)

生态脆弱区贫困与生态环境的博弯分析 祁新华, 叶士琳, 程 暗, 等 (6411)

“世博”背景下上海经济与环境的耦合演化 倪 尧, 岳文泽, 张云堂, 等 $(6418)$

期刊基本参数: CN 11-2031/Q * $1981 * \mathrm{~m} * 16 * 464 * \mathrm{zh} * \mathrm{P} * ¥ 90.00 * 1510 * 55 * 2013-10$

封面图说: 毛乌素沙地南缘沙丘的生物结皮一一生物土壤结皮广泛分布于干旱和半干旱区, 它的形成和发育对荒漠生态系统 生态修复过程产生重要的影响。组成生物结皮的藻类、苔藓和地衣是常见的先锋植物, 它们不仅能在严重干旱缺 水、营养贫㾑恶劣的环境中生长、繁殖, 并且能通过其代谢方式影响并改变环境。其中一个重要的特点是, 生物结皮 表面的凝结水显著大于裸沙。研究表明, 凝结水是除降雨之外最重要的水分来源之一, 在水分极度匮乏的荒漠生态 系统, 它对荒漠生态系统结构、功能和过程的维持产生着重要的影响。

彩图及图说提供: 陈建伟教授 北京林业大学 E-mail: cites.chenjw@163.com 


\title{
生态系统服务研究文献现状及不同研究方向评述
}

\author{
马凤娇 ${ }^{1,2,3}$, 刘金铜 $1,3, *$ A. Egrinya Eneji ${ }^{4}$ \\ (1. 中国科学院遗传与发育生物学研究所农业资源研究中心, 石家庄 050022 ; \\ 2. 中国科学院大学,北京 $100049 ; 3$. 中国科学院 农业水资源重点实验室,石家庄 $050022 ; 4$. 卡拉巴尔大学,尼日利亚)
}

\begin{abstract}
摘要:生态系统服务研究是生态学研究的前沿和热点。对生态系统服务文献发表情况和生态系统服务主要研究方向进行阐述 分析。(1) 通过 Thomson Reuters 公司 ISI Web of knowledge 信息平台提供的 Science Citation Index Expanded 数据库为数据源检 索分析得到:生态系统服务研究从文献数量、作者、国家和机构上近年来都表现出陡增的趋势; 最主要的研究国家为美国、英国、 德国、澳大利亚和中国;涉及 54 个学科,不同的国家侧重的研究领域不同; 来自 258 个期刊, $55 \%$ 的文献集中在 24 个主要期刊 上,主要期刊平均影响因子 5.976。(2) 从生态系统服务评价方法、生态系统内部和生态系统外部驱动因素、基于生态系统服务 的生态系统管理 4 个方面来评述生态系统服务的研究进展。其中生态系统内部驱动主要是指生物多样性和土地利用变化,生 态系统外部驱动因素包括自然因素和人为活动。最后,对生态系统服务研究的发展做了展望。
\end{abstract}

关键词:生态系统服务;文献; 研究方向

\section{A review of ecosystem services and research perspectives}

MA Fengjiao ${ }^{1,2,3}$, LIU Jintong ${ }^{1,2, *}$, A. Egrinya Eneji ${ }^{4}$

1 Center for Agricultural Resources Research, Institute of Genetics and Developmental Biology, Chinese Academy of Sciences, Shijiazhuang 050022, China

2 University of Chinese Academy of Sciences, Beijing 100049, China

3 Key Laboratory of Agricultural Water Resources, Chinese Academy of Sciences, Shijiazhuang 050022, China

4 Department of Soil Science, University of Calabar, Nigeria

\begin{abstract}
Ecosystems services, defined as the benefits that humans derive from the ecosystem, have attracted more attention because increasing human population, economic growth and global consumption pattern have placed an enormous pressure on environmental systems in recent years. Ecosystem services research is a frontier research field bridging ecology, economy and social sciences. Here, we reviewed the ecosystem services and examined the different perspectives on the ecosystem services research, by searching for publications appearing on the ISI Web of Knowledge up to 2012 with the key term 'ecosystem services'. We found 993 studies in the past years by 3134 scientists, working in 1184 research institutions in 80 countries/regions. Literature on ecosystem services was sourced from 258 journals with $55 \%$ of these being concentrated in 24 major journals, which had an average impact factor 5.976. Based on the numbers of articles, authors, institutions and countries related to ecosystem services research, we classified 1980-1997 as the enlightenment stage of ecosystem services, 1998-2004 as the exploring stage, and 2005-2012 as the comprehensive and rapid development stage. The main contributing countries were the United States, the United Kingdom, Germany, Australia and China. Ecosystem services research originated in the United States, which has retained the most important position till today. Other countries joined the ecosystem services research mainly after 2005. The ecosystem services literature covered 54 subjects and different countries focused on different perspectives. The United States has maintained the leadership position, especially in the field of Business Economics. English research had strength in biodiversity conservation. The main perspectives of ecosystem services were that their evaluation method has developed to the integrated model, InVEST (Integrated Valuation
\end{abstract}

基金项目:中国科学院知识创新工程重要方向项目 (KSCX2-EW-J-5)

收稿日期:2013-03-07; 修订日期:2013-07-23

* 通讯作者 Corresponding author.E-mail: jtliu@ sjziam.ac.cn

http : //www.ecologica.cn 
of Ecosystem Services and Tradeoffs), MIMES (Multi-scale Integrated Models of Ecosystem Services) and CICYgreen from traditional methods such as physical quality evaluation method, the market value method and emergy analysis. The internal drivers of ecosystem services included biodiversity and land use changes. Biodiversity loss altered the functioning of ecosystem and their ability to provide society with the goods and services. Land use change impacted ecosystem services provision through altering the habitats, biodiversity and ecosystem processes. The drivers outside the ecosystem included natural factors and human beings. Climate change at the global scale and meteorological disasters at the regional scale were natural factors. Urbanization, unsustainable agricultural development and water management had a negative impact on ecosystem services. However, some ecological restoration practices like Farm to Forest Program had a positive impact. Ecosystem services-based management of the ecosystem would require that the nation took account of ecosystem services as state assets, invested in them, established protected areas and pay for ecosystem services. The trade-off analysis of ecosystem services between providers and beneficiaries and between the different services were the cores of ecosystem management on a regional scale. For deeper research into ecosystem services in the future, we should strengthen the ecosystem dis-services, establish long-term monitoring of the social-ecological system for building a precise social-ecological system integration model, and improve ecosystem services-based management of the ecosystem.

Key Words : ecosystem services; literatures; research perspectives

生态系统服务是指人类从生态系统获得的食物、水、薪柴、精神等所有惠益 ${ }^{[1-3]}$ 。生态系统服务研究是一门连接生态学、经 济学和社会学的交叉性前沿学科 ${ }^{[4]}$ 。随着人口增长、经济发展和全球的消费需求猛增对生态系统造成的压力不断增大,生态 系统服务的供应受到极大的影响 ${ }^{[5]}$ 。从生态系统服务的提出至今短短十几年时间内, 对生态系统服务的研究已经发展成为各 个相关领域的研究前沿。对生态系统服务研究进展的综述从生态系统服务的分类 ${ }^{\left[{ }^{6}\right]}$ 、生态系统服务价值 ${ }^{[7]}$ 、生态系统服务之 间的关系 ${ }^{[8-9]}$ 到将生态系统服务纳人到管理决策 ${ }^{[10]}$ 、不同的研究方向都呈现出快速的发展趋势。本文从生态系统服务研究的 整体视角出发, 先从直观的生态系统服务文献发表情况分析生态系统服务研究的发展程度, 再通过阐述生态系统服务在不同研 究方向上的进展来反映生态系统服务研究现状。

\section{1 生态系统服务研究文献现状}

以 Thomson Reuters 公司的 ISI Web of knowledge 信息平台提供的 Science Citation Index Expanded 数据库为数据源,查询标题 为 “ecosystem services” 的文献,结果发现,从 1980 年第一篇生态系统服务文献的出现到 2012 年,关于生态系统服务研究的文献 共有 993 篇,来自世界 80 个国家/地区, 1184 个科研机构的 3134 位科研工作者。为了进一步了解生态系统服务研究的研究参 与情况、研究涉及领域和研究影响力, 对这些文献进行科学归类划分, 从生态系统服务研究的历年总体情况、主要研究国家的发 文情况、涉及的学科领域和发文期刊 4 个方面分析生态系统服务的研究现状。

1.1 生态系统服务研究的历年总体情况

对生态系统服务研究的文献数量、作者、参与机构和国家的年度分布特点进行分析 (图 1) 发现,以文章的发表情况为主要 依据,生态系统服务研究可划分为 3 个发展阶段:第一阶段为 1980-1997 年,启蒙阶段,该段时间每年发表文献数量极少或者 没有。进行相关研究的学者、机构和国家也非常少,生态系统服务研究尚未被重视;第二阶段为 1998 到 2004 年,探索发展阶 段,该阶段文章每年发表数量增多,且呈明显上升趋势,研究生态系统服务的国家、机构和学者也相应增加,生态系统服务研究 得到初步发展; 第三阶段为 2005 年至今,成熟发展阶段,该阶段文章数量陡增,参与研究的国家、机构和学者越来越多,研究规 模也逐渐扩大,生态系统服务研究进人迅速发展阶段。

1.2 生态系统服务主要研究国家的历年发表文章情况

对 993 篇生态系统服务研究文献的发表来源进行分析发现,美国、英国、德国、澳大利亚和中国 5 个国家对生态系统服务的 研究最为重视,其中美国以 449 篇文献位居第 1 位,英国以 146 篇位于第 2 位,德国、澳大利亚和中国,分别为 94 篇、87 篇和 82 篇。将这个 5 个国家的历年发文数量整理如图 2。从图可以看出,生态系统服务研究起源于美国并一直处于主导地位, 而其他 国家主要是 2005 年以后才加人到生态系统服务研究中, 并以良好的形式稳步增长, 从而也可以推知 2005 年以后生态系统服务 研究文献的飞速增长主要是由于更多科研实力雄厚的国家认识到该项研究的重要性,并积极参与进来展开研究, 推动了该领域 的发展。

从这 5 国的文章质量(表 1) 可以看出,美国各项指标均明显高于其他国家,但每篇平均引用次数只是略高于英国,说明英 国发表的文献数量虽少于美国,但影响力很高。德国、澳大利亚和中国相比前两个国家就差一些,尤其是中国,数量和影响力都 较低,h-指数仅为 14 ,每项平均引用次数仅为 6.88 ; 德国和澳大利亚 $\mathrm{h}$-指数相同,德国引用次数明显更高。 


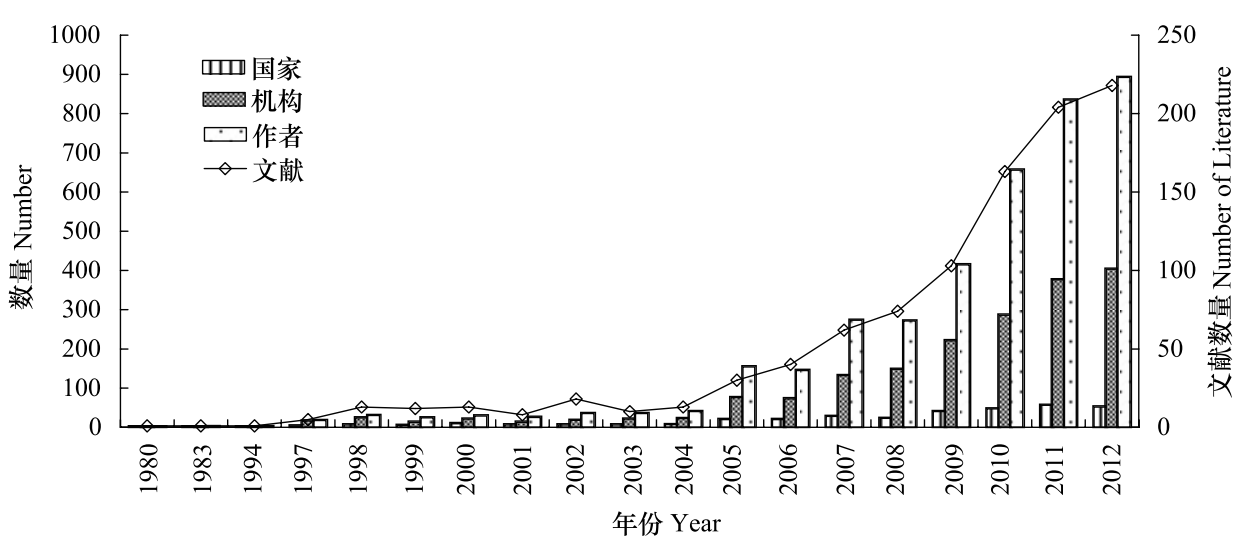

图 12980 到 2012 年历年生态系统服务研究参与情况

Fig.1 Number of published literatures, countries, institutes and authors on ecosystem services between 1980 and 2012

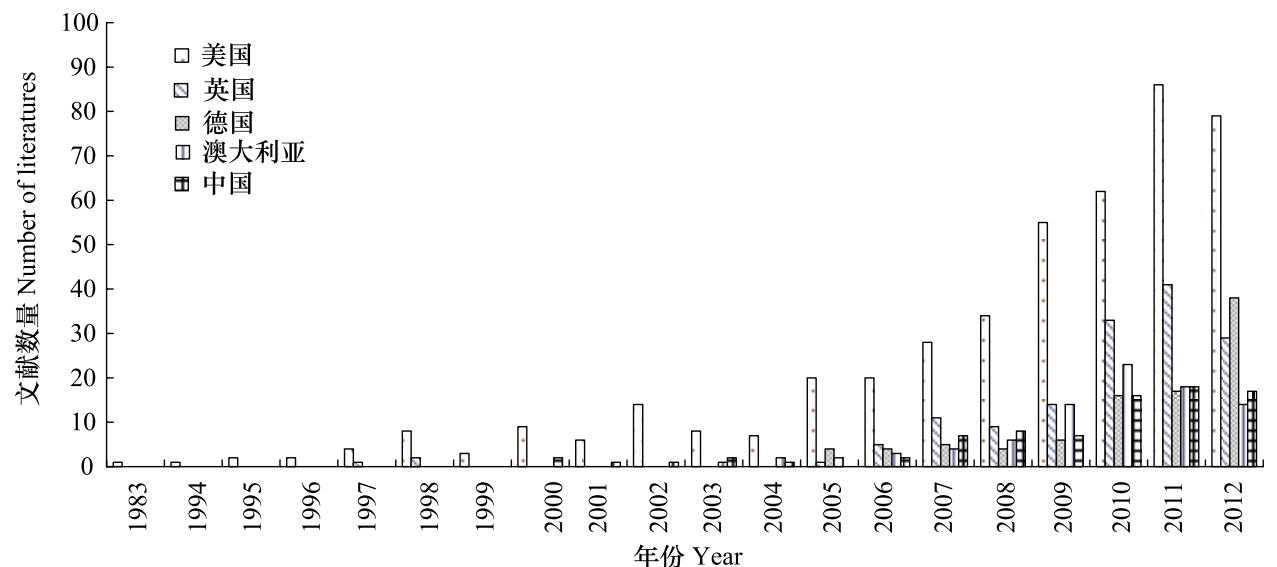

图 2 生态系统服务主要研究国家的历年发表文章情况

Fig.2 Number of published literatures from the main research countries in the past years

表 1 主要论文发表国家的论文影响力比较

Table 1 Characteristic indexes of the published literatures on the main countries

\begin{tabular}{lcccc}
\hline 国家 & $\begin{array}{c}\text { 文献总量 } \\
\text { Number of } \\
\text { publications }\end{array}$ & $\begin{array}{c}\text { 被引频次总计 } \\
\text { Cum of the } \\
\text { times cited }\end{array}$ & $\begin{array}{c}\text { 每篇平均引用次数 } \\
\text { Average c } \\
\text { itations per item }\end{array}$ & $\begin{array}{c}\text { h-指数 } \\
\text { h-index }\end{array}$ \\
\hline 美国 USA & 449 & 12984 & 28.92 & 54 \\
英国 England & 146 & 3692 & 25.29 & 26 \\
德国 Germany & 94 & 1984 & 21.11 & 19 \\
澳大利亚 Australia & 87 & 1291 & 14.84 & 19 \\
中国 China & 82 & 564 & 6.88 & 14 \\
\hline
\end{tabular}

\section{3 生态系统服务涉及学科}

对所有生态系统服务文献以学科方向分类,共涉及 54 个学科,图 3 为各个学科的发文数量,其中将文章数量少于 10 篇的 35 个学科归为其他类。从图 3 可以看出, 文章主要集中于生态环境科学、商业经济、生物多样性保护、科学技术和农业领域,而 54 个研究方向又足以说明生态系统服务是个多学科、多方向的交叉研究领域,涉及的研究内容非常广泛。

针对 5 个主要的研究学科, 5 个最主要的生态系统服务研究国家的分布和发展情况有各自的特点 (图 4)。美国在各个学 科的研究都处于领导地位,但是不同学科的优势程度稍有不同:在生态环境科学领域多出其他国家两倍以上的研究文献数量; 而在商业经济领域比其他几个国家所有的研究总和还要多两倍以上, 说明商业经济研究方向是美国主导; 在农业领域的优势也 类似商业经济。而英国的研究除生态环境科学这个学科以外,在生物多样性保护方向的研究贡献非常突出, 文献数量几乎和美 国持平,这和英国资深的理论生态学学术底蕴密切相关,生物多样性保护是生态学领域的前沿也是英国科研工作的重点和优 
势。德国、澳大利亚和英国的分布情况相似, 只是数量略少。中 国的研究方向和美国更接近,除生态环境科学以外, 最多的文献 就是涉及商业经济和科学技术方面, 只是文献数量远低于美国。

1.4 生态系统服务研究的主要期刊分布

文献来源期刊与文献的研究方向高度相关, 统计结果显示, 生态系统服务文献来源于 258 个期刊, 其中 153 个期刊只发表 过一篇文章, 占全部期刊的 $59 \%$, 而 209 个期刊发文数量不到 5 篇, 占 $81 \%$,其发表的文章总量仅占全部文章数量的 $29.6 \%$ 。超 过 10 篇以上的期刊有 24 个, 占期刊总数的 $9.3 \%$,但发表的文献 数量占全部文献数量的 $55 \%$, 其中比重最大的是 Ecological Economics 占到文献总量的 $13 \%$ 。这 24 个期刊包括了生态系统 服务主要的研究方向, 平均影响因子是 5.967 , 其中包括综合性 前沿刊物 Science、Proceedings of the National Academy of Sciences of the United States Of America,生态学前沿刊物 Ecology Letters、 Frontiers in Ecology and the Environment、Conservation Biology Journal of Applied Ecology、Ecosystems, 可见生态系统服务研究在 生态学领域占据重要的研究地位和影响力。

\section{2 生态系统服务的研究方向}

从 20 世纪 70 年代 SCEP ( Study of Critical Environmental Problems) 的报告中首次提出环境服务功能的概念 ${ }^{[11]}$, 到 1997 年 Costanza 在《Nature》上发表的文章:全球生态系统服务与自然 资本的价值估算 ${ }^{[1]}$ 和 Daily 出版的书籍《生态系统服务: 人类社 会对自然生态系统的依赖性 $\rangle^{[2]}$, 再到由联合国资助、为期 4 年 的国际合作项目千年生态系统评估于 2005 年完成全部评估工

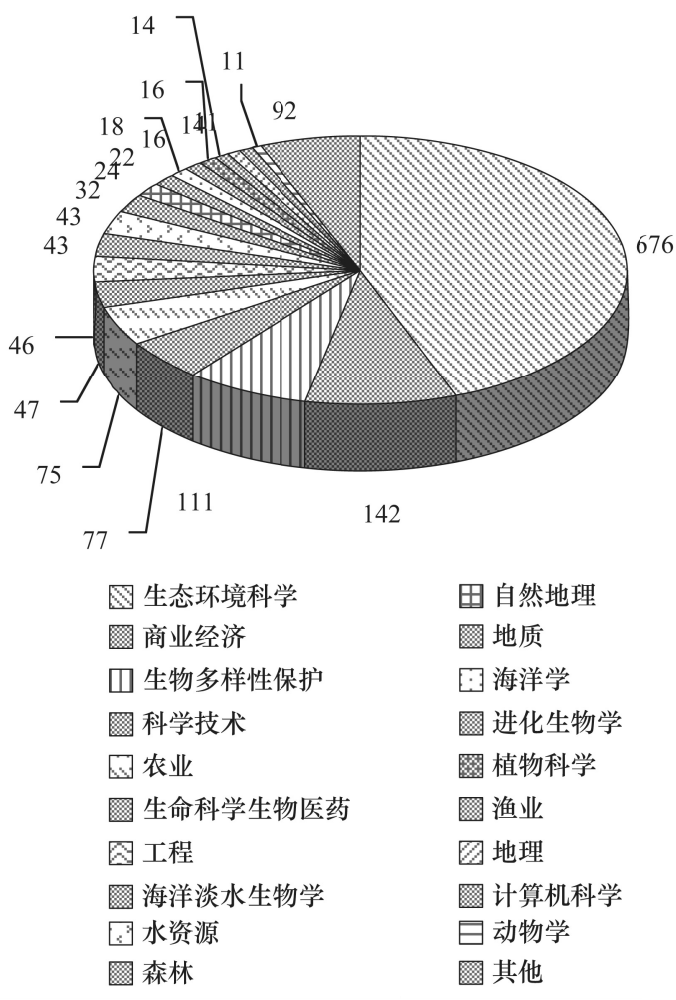

图 3 生态系统服务不同学科方向的文献数量分布图

Fig.3 Direction pie of ecosystem services literature numbers in different disciplines 作 ${ }^{[3]}$, 生态系统服务研究经历了启蒙、探索到迅速发展的历程 (与图 1 结果相符),生态系统服务的研究内容从单一的生态系统 服务价值评估发展到生态结构、过程、功能的机理探究和生态系统的科学管理。2010 年完成的由联合国环境规划署主持,八国 集团 G8(Group 8) 和五大发展中经济体发起的全球性研究项目:生态系统和生物多样性的经济学( TEEB) 将自然科学、经济学 和政策 3 个领域融合起来,分别对国家和国际决策者、本地决策者和管理者、企业、市民 4 个群体给出具体的实践指导报告,是 后千年生态系统评估阶段的重要研究成果 ${ }^{[12-13]}$ 。生态系统服务是个多学科交叉的前沿命题, 对其深人探究需要不同背景的科 研工作者,把握自己在这个研究体系中的位置和作用。本文对生态系统服务研究的各个不同方向进行归纳整理,将生态系统服 务研究的总体框架概括如图 5 , 以生态系统服务研究为核心,生态学方向的研究涉及不同的生态系统结构(如生态系统的土地 利用类型、生态系统中的生物多样性等)对应着不同的生态系统过程(如生态系统的碳、氮、水等循环过程、光合过程等),在此 过程上产生不同的生态系统服务; 而生态系统服务在社会管理学领域的研究是如何将生态系统服务纳人到决策中,通过决策反 馈给生态系统,使之能够为人类提供更优的生态系统服务。基于此研究框架, 本文从生态系统服务评价方法、生态系统内部外 部驱动因素以及生态系统管理 4 个方向分别展开介绍。

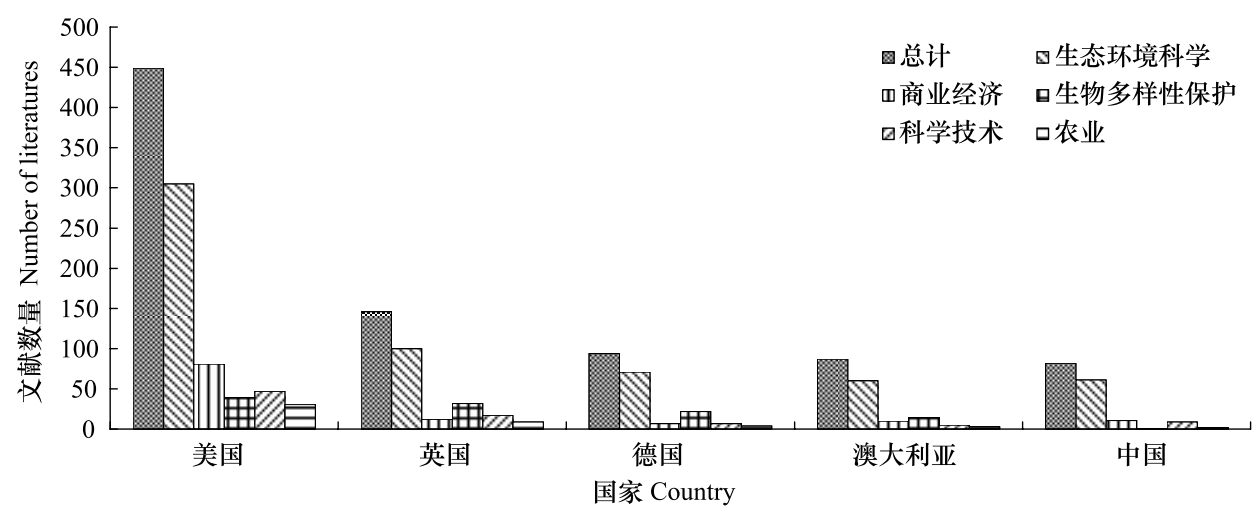

图 4 主要发文国家在主要学科上文章的分布情况

Fig.4 Distribution of the main disciplines literatures on the main countries 


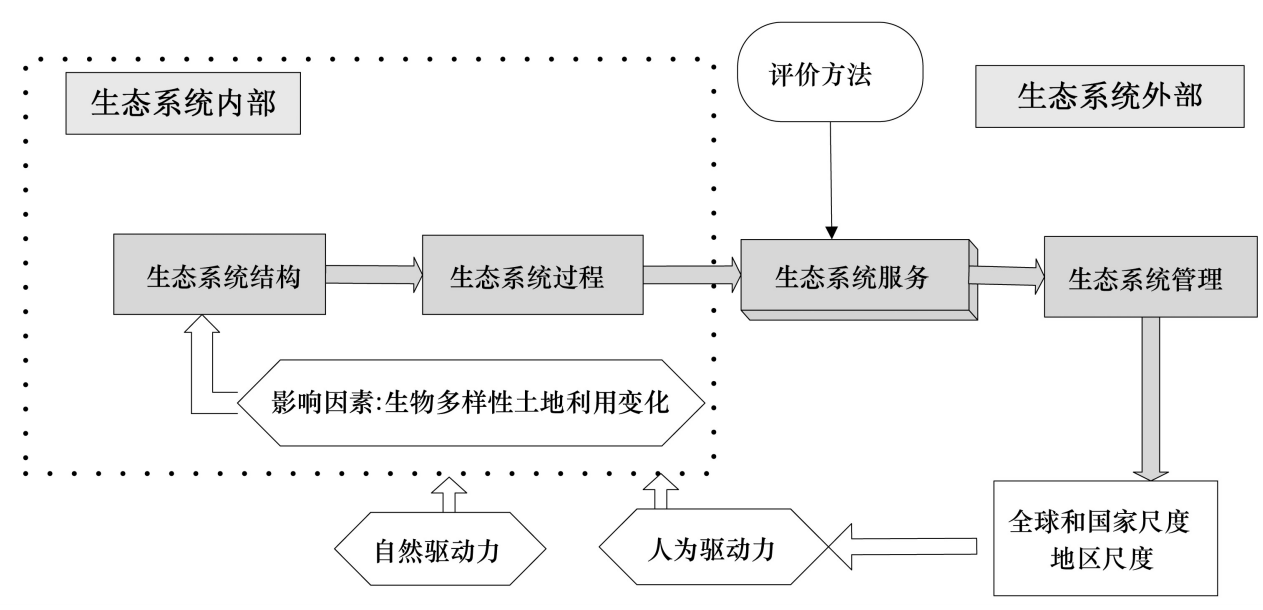

图 5 生态系统服务研究框架

Fig.5 Conceptual framework of ecosystem services

\section{1 生态系统服务的评价方法}

传统的生态系统服务评价方法包括:物质量评价法、市场价值化方法和能值分析法。物质量评价法通过统计数据、问卷调 查、实验测定等方法, 以物质量的方式给出生态系统提供给人类的服务 ${ }^{[14-17]}$ 。生态系统服务的市场价值化方法包括两个方向： （1）依据环境经济学理论,基于市场对生态系统服务进行定价 ${ }^{[18-21]}$; (2) 基于生态系统类型和各类型生态系统单位面积提供服 务的价值求和得到总价值 ${ }^{[36]}$ 。能值分析法是对无法货币化的自然资本、不同种类的能量统一成太阳能量来评估生态系统服务 的价值 ${ }^{[22-24]}$ 。

基于生态经济过程的生态系统服务综合评估模型是生态系统服务评价的新工具。其中被广泛认可和推广的是由美国斯坦 福大学、世界自然基金会 WWF 和大自然保护协会 $(\mathrm{TNC})$ 在自然资本项目的资助下联合开发出来的生态系统服务和交易的综 合评估模型( InVEST)。InVEST 模型基于 GIS 平台, 是一个将自然资本纳人到决策中的主导工具。通过咨询利益相关者确定出 不同的情景,在该情景下利用生物物理模型给出生态系统服务的分布图、权衡关系曲线和资产负债表; 再通过经济模型,模拟出 美元价值、给出分布图、权衡关系曲线和资产负债表; 最终再将生物物理模型、经济模型模拟的结果反馈利益相关者。模型已经 成功应用于战略性环境评估、海洋空间规划、流域生态补偿、减贫战略文件、减排和补偿、碳补偿。在中美洲的伯利兹城海岸、美 国的夏威夷、加利福尼亚和俄勒冈州、非洲的坦桑尼亚, 以及我国的澜沧江流域、西苕溪流域、北京山区等多个地区成功应 用 ${ }^{[25-26]}$ 。另外, 由美国弗蒙特大学冈德生态经济研究所 Robert Costanza 及其科研团队开发研制的多尺度生态系统服务综合模 型(简称 MIMES) ${ }^{[27]}$ 和由美国林业署发行,依托 $3 S$ 技术,基于 ERSI 公司的 GIS 软件 ArcView3.x 开发的扩展功能模块 CITYgreen 模型也有较多的应用 ${ }^{[28]}$ 。

\section{2 生态系统内部生态系统服务的驱动因素}

2.2.1 生物多样性和生态系统服务之间的关系

生物多样性是生态系统服务提供的生态系统结构基础, 提高从生物多样性和生态系统服务而来的福祉,已经作为生物多样

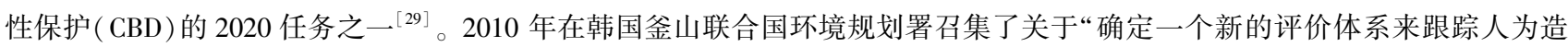
成的生态系统改变” 的会议, 搭建了生物多样性和生态系统服务的政府平台 IPBES, 为国际合作研究、资源共享、社会科学与自 然科学的合作提供了可能 ${ }^{[30]}$ 。

不同的研究结果表明:生物多样性和生态系统不同服务之间的关系不同,某些服务 (如渔业、牧草产量; 碳同化、土壤形成) 和生物多样性高度正相关; 某些服务 (如作物产量、昆虫控制) 和生物多样性的关系复杂,研究结果没有达成共识; 很多服务和 生态多样性的研究尚未开展;极个别的服务 (如淡水净化服务) 甚至和生物多样性呈负相关 ${ }^{[31]}$ 。

生物多样性和生态过程之间存在严格的定量关系,如生物多样性的增加对土壤侵蚀、氮素循环都有明确的正相关关系 ${ }^{[32]}$ 。 以农田生态系统为例, 景观集约化可能干扰生物昆虫控制、作物授粉等过程; 局部集约化也会影响生物昆虫控制、草地生物量、 授粉、植物人侵的抵抗 ${ }^{[33]}$; 田间轮作实验发现轮作中的物种数量越高, 作物产量和土壤无机态氮的可利用性越高 ${ }^{[34]}$; 通过农业 管理提高生物多样性可以改善栖息地的生物多样性,提高农田生态系统提供的各项服务 ${ }^{[35]}$ 。

2.2.2 土地利用与覆被变化影响下生态系统服务研究

土地利用/覆被变化通过改变生物生境和资源分布、改变生物多样性及生态系统过程 3 条途径影响生态系统服务,其反映 了人与自然相互影响最直接的关系, 是影响生态系统服务的重要驱动力之一。如果用基于生态系统类型和各类生态系统单位 面积提供服务价值来评价生态系统服务,土地利用类型则直接决定着生态系统服务价值的多少。通过土地利用变化来评价生 
态系统服务的研究在全球尺度 ${ }^{[1]}$ 、国家尺度 ${ }^{[36]}$ 、区域尺度 ${ }^{[37]}$ 和地区尺度 ${ }^{[36]}$ 内广泛开展。但这类方法缺乏生态服务的生态学 机制探究,并没有考虑各种土地利用类型的空间异质性和每种土地利用类型非线性提供服务的过程机理,使评估结果缺乏科学 上的确定性。而基于实验观测数据的生态过程评价生态系统服务对土地利用变化的响应, 可以获得更可信的评价结果 ${ }^{[38]}$ 。

2.3 生态系统外部生态系统服务的驱动因素

2.3.1 自然影响因素

气候变化是生态系统服务的一个重要外部驱动力。在欧洲,通过生态模型模拟了气候和土地利用变化对欧洲的生态系统

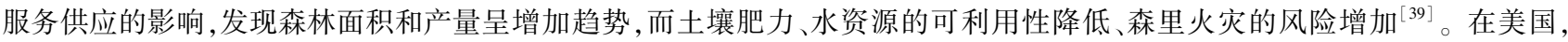
Michael 等预测了气候变化对水资源相关的生态系统服务的影响 ${ }^{[40]}$; 气候变化对加利福尼亚地区陆地分布和其影响下的生态 系统服务 (碳储量和自然牧草的产量) 变化的研究发现: 在不同的预测情景下,使用生物物理模型研究了碳储量和牧草产量两 项服务, 发现生态系统服务的提供和价值都是降低的 ${ }^{[41]}$ 。在中国, 3 种气候变化情景下中国森林生态系统服务价值的研究发 现:全球变暖背景下,中国森林面积虽然减少,但生态系统服务价值却明显增加 ${ }^{[42]}$ 。

对于极端天气等气象灾害对生态系统服务的影响,如中国 98 洪水对鄱阳湖区生态系统服的影响,通过洪水以及洪水后的 退田还湖工程使鄱阳湖的土地利用发生了重要的改变,使洪涝灾害发生后的 2 年时间里,生态系统服务功能整体提升了 $8.5 \%{ }^{[43]}$ 。

\subsection{2人为影响因素}

城市化通过对区域土地利用、景观格局、生态过程、生物物理、生物化学循环等强烈影响着区域生态系统结构、功能和服 务 ${ }^{[4]}$ 。城市化程度越高,生态系统服务功能越低。Schneider 等对美国玉米种植带的 3 个城市在过去 (1992-2001) 和将来 (2001-2030) 城市扩展计划对生态系统产品和服务的影响做了评价。使用农田生态系统模型模拟了高、中和低密度城市面积 情景, 结果表明: 扩大的城市面积对城市调节气候和洪水的能力有显著性影响。高密度城市面积的土壤温度比自然管理的生态 系统高 $6{ }^{\circ} \mathrm{C}$ 。居民区草坪的增加使径流增加了 $15 \%-48 \%$,降低了调节洪水的能力 ${ }^{[45]}$ 。

农业开发、水利工程开发会影响生态系统服务的供应。在某些供给服务提高的同时,也会带来农业水污染、地下水位下降、 泥沙淤积等环境成本。肖建红等对全国水坝的评价结果是防洪和水利发电是其主要正面效应,而泥沙淤积是最大的负面效 应 ${ }^{[46]}$ 。澜沧江漫湾水电站对生态系统服务影响评价结果是水电开发的生态环境效益与生态环境成本的比值为 $1: 5.56^{[47]}$ 。裴 厦等总结了水库对河流生态系统服务功能的正负效应: 水库蓄水可以提高调蓄洪水能力、增加灌溉用水、生活用水、工业用水、 水库养鱼、增加航运、发电量、旅游, 水库发电可以调节大气成分, 这些都是正效应。而水库占地导致了破坏生境、水库移民、文 化遗产损失; 泥沙淤积导致阻塞营养运移、周围土壤退化; 改变河道使生物多样性丧失、营养运移方式改变; 水温改变使生境丧 失;河流静止减弱河流自净能力, 都是其负效应 ${ }^{[48]}$ 。

合理的人类干预却可以提高生态系统服务,如退耕还林等生态恢复工程。Rey Benayas 等通过对全球 89 个生态恢复评价 的 meta 分析表明生态恢复增加 44\% 的生物多样性和 $25 \%$ 的生态系统服务。生物多样性和生态系统服务的增量正相关, 以提高 生物多样性为目的的生态恢复行为可以增加生态系统服务的供给 ${ }^{[49]}$ 。

2.4 基于生态系统服务的生态系统管理

2.4.1 全球和国家尺度上生态系统服务管理

准确的监控和度量生态系统服务提供量和需求量,可以确保管理者科学的管理自然资本。生态系统提供的部分服务(如 调节服务), 由于没有进人市场, 就没有价格,这些服务就不能在传统的会计程序(如通用的标准国家账户体系) 中予以衡量。 将生态系统服务完全整合到国家经济账户中可能是一个长期的过程 ${ }^{[13]}$ 。以生态系统服务为核心的可持续发展核算发展到绿 色 GDP 的计算, Maler K. G. 给出了将生态服务纳人到资产核算中的方法和具体步骤和实例 ${ }^{[50]}$ 。

国家需要对生态系统进行投资。第一,对生态系统能够提供稳定服务的能力投人必要的保护资金,如投资 110 万美元用于 恢复和保护越南的红树林,但节省了海堤维护费 730 万美元 ${ }^{[51]}$ 。第二,投资各类保护区需要投人管理成本,但是可以保证各类 型生态系统服务功能, 从全球尺度来看,其效益远远超过投人。如果生态系统受损已经发生就要恢复受损的生态系统, 大范围 的恢复工作中,政府投人和利益相关方的协同就尤为重要 ${ }^{[13]}$ 。第三, 为生态系统服务付款 (PES) 的思想受到了极大的重 视 ${ }^{[52]}$, 有些项目也在尝试将其应用到实践中。如, 在中国实施了全球最大的 PES 计划之一一一退耕还林 ${ }^{[53]}$; 在欧洲, 欧盟每年 花费 20 亿欧元用于支持 PES 计划 (称为农业环境和森林环境计划) ${ }^{[13]}$; 在美国佛罗里达牧场环境服务项目 FRESP (Florida Ranchlands Environmental Services Project) 设计了一个生态环境付款方案, 由国家机关对佛罗里达私人牧场支付环境服务一一水 储量和降低磷负荷的费用 ${ }^{[54]}$ 。

2.4.2 地区尺度上生态系统服务的权衡管理

为了对生态系统服务在空间上进行权衡管理,在生态学认知上定义生态系统服务提供者 (ESP), 服务提供单元 (SPU) ${ }^{[55]}$, 以及 SPU-ESP 连续体概念来研究生态系统服务, 从种群、功能群和群落水平上阐述了服务提供者的概念。对其清晰的定义和 准确的定量是将服务应用到人类福利需求的关键 ${ }^{[56]}$ 。以加利福尼亚野生蜜蜂传粉服务的管理计划为例, 以野生蜜蜂为一个 
$\mathrm{ESP}$,研究发现一个农场 $1-2 \mathrm{~km}$ 范围内野生蜜蜂栖息地的比例和授粉服务能力的函数关系,基于这个理论,为土地管理者提 供管理方案 ${ }^{[57]}$ 。而 Carcia 等将生态系统服务受益者纳人到生态系统服务评价体系当中。在西班牙西南部一个社会-生态系统 中进行分析,生态系统服务提供者 ESP 是不同的水生植物功能群,生态系统服务受益者 (ESB) 是在该地区居住或者来旅游的不 同利益相关方。生态学研究人员从生态系统结构和过程上分析生态系统提供的服务,而生态系统服务受益者用社会经济学的 方法给出生态系统服务的价值, 最终探索了连接生态系统服务经济价值和功能特征传递的关系 ${ }^{[58]}$ 。

对于生态系统服务之间的权衡管理是生态系统管理的实质,单单强调某一种服务的提高往往导致其他服务的降低。对生 态系统服务之间进行权衡分析的前提是清楚了解生态系统不同服务之间的关系。在某一调控措施(驱动力) 的作用下,不同的 生态系统服务的响应是不一样的,有些服务会增加,而有些服务会减少,如施肥情况下,作物产量服务会增加,而附近水体可能 会因为肥料淋失而被污染, 供水服务会降低。另外,不同的服务之间也会产生作用关系, 如修复湿地驱动下, 调节洪水服务会增 强, 之后作物产量服务也会提高; 而保护性耕作情况下,会提高土壤侵蚀控制服务,从而提高作物产量服务, 而作物产量服务的 提高又返回来促进侵蚀控制服务的增强 ${ }^{[9]}$ 。正确的处理不同生态系统服务的响应关系,使生态系统提供整体最优的服务, 是 生态系统服务权衡管理的最终目的。

\section{3 研究展望}

生态系统服务作为一个新兴的研究领域,在不同的研究方向上都取得了显著的成绩,评价方法上从单一的生态物理、环境 经济方法发展到综合评估模型; 生态系统服务的驱动因素上,从土地利用类型对生态系统服务的影响,深人到探究生物多样性、 自然因素和人类活动对生态系统服务的影响; 基于生态系统服务的生态系统管理在理论和实践上都进行了尝试性探索。但与 人类的需求相比还存在很大的差距, 将来需要在以下方面继续深人研究和实践。

(1) 生态系统为人类提供服务的同时,某些生态系统在某些时空范围内也为人类提供负服务,一些生态系统服务研究人员 已经注意到这个问题 ${ }^{[59]}$, 如城市生态系统 ${ }^{[60-61]}$ 和农田生态系统的研究 ${ }^{[62]}$, 对生态系统排放温室气体、有机污染物、土壤盐渍 化、地下水污染等负服务进行了总结和评估,但对生态系统负服务的实际研究尚处于探索阶段,需要扩大生态系统负服务的研 究对象,建立标准的研究指标体系和评估方法。

(2) 权衡不同区域生态系统服务的消费、分配与补偿, 将生态系统系统提供的服务价值纳人到自然资本的核算体系 ${ }^{[10,63]}$, 构建绿色 GDP 的经济评估体制, 是将生态系统服务提升到国家决策层面,并切实影响各个利益相关方的有效调控手段。建立 标准完善合理的自然资本核算体系是环境经济学、经济学家的重要工作。

(3) 探究生态系统服务的生态学形成机制, 对生态系统服务的准确科学评估,需要基于社会-生态体系的长期监测, 构建精 确的社会-生态体系集成模型。只有长期的一手观测和调查资料才能真实反映生态系统和人类社会的现状,而将数据整合到集 成模型中,才能从生态过程机制上得到可信的整体的生态系统服务供给情况。

(4) 各种服务之间的内在联系以及生态系统服务与生态系统外部、内部驱动力之间的效应研究是科学管理生态系统的前 提和依据 ${ }^{[64-65]}$ 。不同服务之间的权衡、不同驱动力下引起的不同生态系统服务的变化情况需要权衡, 如何将生态系统提供的 整体生态系统服务最优,更多的利用生态系统服务之间的协同作用,最大限度的推行共赢模式,是生态系统管理者追求的最终 目标。

\section{References:}

[ 1 ] Costanza R, dArge R, deGroot R, Farber S, Grasso M, Hannon B, Limburg K, Naeem S, Oneill R V, Paruelo J, Raskin R G, Sutton P, vandenBelt M. The value of the world's ecosystem services and natural capital. Nature, 1997, 387( 6630): 253-260.

[ 2 ] Daily G C. Nature's Services: Societal Dependence on Natural Ecosystems. Washington D C: Island Press, 1997.

[ 3 ] Millennium Ecosystem Assessment. Ecosystems and Human Well-Being. Washington D C: Island Press, 2005.

[ 4 ] Burkhard B, Petrosillo I, Costanza R. Ecosystem services-bridging ecology, economy and social sciences. Ecological Complexity, 2010, 7( 3) : 257-259.

[ 5 ] Seppelt R, Dormann C F, Eppink F V, Lautenbach S, Schmidt S. A quantitative review of ecosystem service studies: approaches, shortcomings and the road ahead. Journal of Applied Ecology, 2011, 48(3) : 630-636.

[ 6 ] Fisher B, Turner R K, Morling P. Defining and classifying ecosystem services for decision making. Ecological Economics, 2009 , 68(3) : 643-653.

[ 7 ] Fu B J, Su C H, Wei Y P, Willett I R, Lu Y H, Liu G H. Double counting in ecosystem services valuation: causes and countermeasures. Ecological Research, 2011, 26(1): 1-14.

[ 8 ] Power A G. Ecosystem services and agriculture: tradeoffs and synergies. Philosophical Transactions of the Toyal Society B: Biological Sciences, 2010, 365( 1554): 2959-2971.

[ 9 ] Bennett E M, Peterson G D, Gordon L J. Understanding relationships among multiple ecosystem services. Ecology Letters, 2009, 12 ( 12) : 1394-1404.

[10] Daily G C, Polasky S, Goldstein J, Kareiva P M, Mooney H A, Pejchar L, Ricketts T H, Salzman J, Shallenberger R. Ecosystem services in 
decision making: time to deliver. Frontiers in Ecology and the Environment, 2009, 7(1) : 21-28.

[11] SCEP. Man's Impact on the Global Environment. Cambridge: MIT Press, 1970.

[12] The Economics of Ecosystem and Biodiversity: Ecological and Economic Foundations. London and Washington: Island Press, 2010.

[13] TEEB. The Economics of Ecosystems and Biodiversity in National and International Policy Making. London: Island Press, 2011.

[14] Olschewski R, Klein A M, Tscharntke T. Economic trade-offs between carbon sequestration, timber production, and crop pollination in tropical forested landscapes. Ecological Complexity, 2010, 7(3): 314-319.

[15] Egoh B, Reyers B, Rouget M, Richardson D, Le Maitre D C, van Jaarseld A S. Mapping ecosystem services for planning and management. Agriculture, Ecosystems and Environment, 2008, 127(1): 135-140.

[16] Naidoo R, Ricketts T H. Mapping the economic costs and benefits of conservation. PLoS Biology, 2006, 4( 11): 2153-2156.

[17] Jenkins W A, Murray B, Kramer R, Faulkner S. Valuing ecosystem services from wetlands restoration in the Mississippi Alluvial Valley. Ecological Economics, 2010, 69(5): 1051-1061.

[18] Yang W, Chang J, Xu B, Peng C H, Ge Y. Ecosystem service value assessment for constructed wetlands: A case study in Hangzhou, China. Ecological Economics, 2008, 68(1): 116-125.

[19] Seidl A F, Moraes A S. Global valuation of ecosystem services: application to the Pantanal da Nhecolandia, Brazil. Ecological Economics, 2000, $33(1): 1-6$.

[20] Chen Z X, Zhang X S. Value of ecosystem services in China. Chinese Science Bulletin, 2000, 45(10): 870-876.

[21] Li R Q, Dong M, Cui J Y, Zhang L L, Cui Q G, He W M. Quantification of the impact of land-use changes on ecosystem services: A case study in Pingbian County, China. Environmental Monitoring and Assessment, 2007, 128(1/3) : 503-510.

[22] Odum H T, Odum E P. The energetic basis for valuation of ecosystem services. Ecosystems, 2000, 3(1): 21-23.

[23] Geber U, Björklund J. The relationship between ecosystem services and purchased input in Swedish wastewater treatment systems-a case study. Ecological Engineering, 2002, 19(1): 97-117.

[24] Porter J, Costanza R, Sandhu H, Sigsgaard L, Wratten S. The value of producing food, energy, and ecosystem services within an agro-ecosystem. Ambio: A Journal of the Human Environment, 2009, 38(4): 186- 193.

[25] Nelson E, Mendoza G, Regetz J, Polasky S, Tallis H, Cameron D, Chan K, Daily G, Goldstein J, Kareiva P, Lonsdorf E, Naidoo R, Naidoo R, Ticketts T, Shaw M. Modeling multiple ecosystem services, biodiversity conservation, commodity production, and tradeoffs at landscape scales. Frontiers in Ecology and the Environment, 2009, 7(1): 4-11.

[26] Chen L, Xie G D, Zhang C S, Pei S, Fan N, Ge L Q, Zhang C X. Modelling ecosystem water supply services across the Lancang River Basin. Journal of Resources and Ecology, 2011, 2(4) : 322-327.

[27] Costanza R, Leemans R, Boumans R, Gaddis E. In Sustainability or Collapse? An Integrated History and Future of People on Earth. Cambridge: MIT Press, 517-517.

[28] American Forests. CITYgreen-Calculating the Value of Nature (Version 5. 0). Washington D C: American Forests, 2000.

[29] Perrings C, Naeem S, Ahrestani F, Bunker D E, Burkill P. Ecosystem services for 2020. Science, 2010, 330 ( 6002) : $323-324$.

[30] Perrings C, Duraiappah A, Larigauderie A, Mooney H. The biodiversity and ecosystem services science-policy interface. Science, 2011, 331 (6021) : 1139-1140

[31 Cardinale B J, Duffy J E, Gonzalez A, Hooper D U, Perrings C, Venail P, Narwani A, Mace G M, Tilman D, Wardle D A, Kinzing A P, Daily G C, Loreau M, Grace J B, Larigauderie A, Srivastava D S, Naeem S. Biodiversity loss and its impact on humanity. Nature, 2012, 486(7401) : 59-67.

[32] Balvanera P, Pfisterer A B, Buchmann N, He J S, Nakashizuka T, Raffaelli D, Schmid B. Quantifying the evidence for biodiversity effects on ecosystem functioning and services. Ecology Letters, 2006, 9(10): 1146-1156.

[33] Tscharntke T, Klein A M, Kruess A, Steffan-Dewenter I, Thies C. Landscape perspectives on agricultural intensification and biodiversity-ecosystem service management. Ecology Letters, 2005, 8(8): 857-874.

[34] Smith R G, Gross K L, Robertson G P. Effects of crop diversity on agroecosystem function : crop yield response. Ecosystems, 2008, 11 ( 3 ) : 355-366.

[35] Robertson G P, Swinton S M. Reconciling agricultural productivity and environmental integrity: a grand challenge for agriculture. Frontiers in Ecology and the Environment, 2005, 3(1): 38-46.

[36] Li T H, Li W K, Qian Z H. Variations in ecosystem service value in response to land use changes in Shenzhen. Ecological Economics, 2010, 69 (7) : 1427-1435.

[37] Yuan Y, Liu J T, Liu H T, Tan L M, Liu H J. Spatial-temporal variation of ecosystem services in response to land use changes: Case study in the 38 degrees N ecological transect of Northern China. Journal of Food Agriculture and Environment, 2013, $10(2)$ : 794-802.

[38] Ge J, Wu N, Gao J X, Wang X H, Sudebilige, Zhang C, Ennaanay D, Tian M R. Responses and weigh of multi-ecosystem services and its economic value under different land cover scenarios: a case study from Ertan water control pivot in Yalong River. Acta Ecologica Sinica, 2012 , 32 (9) : 2629-2639 
[39] Schröter D, Cramer W, Leemans R, Prentice I C, Araújo M B, Arnell N W, Bondeau A, Bugmann H, Carter T R, Gracia C A, de la VegaLeinert A C, Erhard M, Ewert F, Glendining M, House J I, Kankaanpaa S, Klein R J, Lavorel S, Lindner M, Metzger M J, Meyer J, Mitchell T D, Reginster I, Rounsevell M, Sabate S, Sitch S, Smith B, Smith J, Smith P, Sykes M T, Thonicke K, Thuiller W, Tuck G, Zaehle S, Zierl B. Ecosystem service supply and vulnerability to global change in Europe. Science, 2005, 310( 5752) : $1333-1337$.

[40] Friedel M J. Climate change effects on ecosystem services in the United States-issues of national and global security// Baba A, Gündüz O, Friedel M J, Tayfur G, Howard K W F, Chambel A. Climate Change and its Effects on Water Resources. Netherlands: Springer, 2011 : 17-24.

[41] Shaw M R, Pendleton L, Cameron D R, Morris B, Bachelet D, Klausmeyer K, MacKenzie J, Conklin D R, Bratman G N, Lenihan J, Haunreiter E, Daly C, Roehrdanz P R. The impact of climate change on California's ecosystem services. Climatic Change, 2011, 109( 1) : 465-484.

[42] Zhang M J, Zhou L H. The influence of climate change on the value of Chinese forest ecosystem services. Journal of Arid Land Resources and Environment, 2004, 18(2): 40-43.

[43] Long X, Zhen L, Cheng S K, Yan B Y, Ma L, Pan Y, Jiang L G, Yang L, Cao X C. Impact of the 1998 Flood on ecosystem services in the Poyang Lake Region, China. Resources Science, 2011, 34(2) : 220-228.

[44] Zhou Z X. Conceptual mechanism model of impact of urbanization on ecosystem service and case study. Research of Soil and Water Conservation, $2012,18(5): 32-38$.

[45] Schneider A, Logan K E, Kucharik C J. Impacts of urbanization on ecosystem goods and services in the U. S. Corn Belt. Ecosystems, 2012, 15 (4) : 519-541

[46] Xiao J H, Shi G Q, Mao C M, Wang M, Xing Z X. Evaluation of effects of dams on river ecosystem service functions in China. Acta Ecologica Sinica, 2007, 27(2): 526-537.

[47] Wei G L, Cui B S, Dong S W, Yang Z F. Impact of hydropower development on river ecosystem service: a case study from the Manwan Hydropower Project. Acta Scientiae Circumstantiae, 2008, 28(2) : 235-242

[48] Pei S, Xie G D, Lu C X, Zhang Y S, Chen L. Cumulative effects of cascade hydropower development on river ecosystem services: A case study of the Maotiaohe River. Resources Science, 2011, 33(8): 1469-1474.

[49] Benayas J M R, Newton A C, Diaz A, Bullock J M. Enhancement of biodiversity and ecosystem services by ecological restoration: a meta-analysis. Science, 2009, 325(5944) : 1121-1124.

[50] Mäler K G, Aniyar S, Jansson A. Accounting for ecosystem services as a way to understand the requirements for sustainable development. Proceedings of the National Academy of Sciences of the United States of America, 2008, 105(28) : 9501-9506.

[51] Tallis H, Kareiva P, Marvier M, Chang A. An ecosystem services framework to support both practical conservation and economic development Proceedings of the National Academy of Sciences of the United States of America, 2008, 105( 28 ) : 9457-9464.

[52] Kinzig A P, Perrings C, Chapin F S, Polasky S, Smith V K, Tilman D, Turner B L. Paying for ecosystem services-promise and peril. Science, $2011,334(6056): 603-604$

[53] Liu J G, Li S X, Ouyang Z H, Tam C, Chen X D. Ecological and socioeconomic effects of China's policies for ecosystem services. Proceedings of the National Academy of Sciences of the United States of America, 2008, 105(28) : 9477-9482.

[54] Bohlen P J, Lynch S, Shabman L, Clark M, Shukla S, Swain H. Paying for environmental services from agricultural lands: an example from the northern Everglades. Frontiers in Ecology and the Environment, 2009, 7(1): 46-55.

[55] Luck G W, Daily G C, Ehrlich P R. Population diversity and ecosystem services. Trends in Ecology \& Evolution, 2003, 18 (7) : 331-336.

[56] Luck G W, Harrington R, Harrison P A, Kremen C, Berry P M, Bugter R, Dawson T P, Bello F, Diaz S, Feld C K, Haslett J R, Hering D, Kontogianni A, Lavorel S, Rounsevell M, Samways M J, Sandin L, Settele J, Sykes M T, Hove S, Vandewalle M, Zobe M. Quantifying the contribution of organisms to the provision of ecosystem services. Bioscience, 2009, 59(3) : 223-235.

[57] Kremen C. Managing ecosystem services: what do we need to know about their ecology?. Ecology Letters, 2005, 8( 5) : 468-479.

[58] García-Llorente M, Martín-López B, Díaz S, Montes C. Can ecosystem properties be fully translated into service values? An economic valuation of aquatic plant services. Ecological Applications, 2011, 21(8) : 3083-3103.

[59] Limburg K E, Luzadis V A, Ramsey M, Schulz K L, Mayer C M. The good, the bad, and the algae: Perceiving ecosystem services and disservices generated by zebra and quagga mussels. Journal of Great Lakes Research, 2010, 36(1) : 86-92.

[60] Escobedo F J, Kroeger T, Wagner J E. Urban forests and pollution mitigation: analyzing ecosystem services and disservices. Environmental Pollution, 2011, 159(8): 2078-2087.

[61] Pataki D E, Carreiro M M, Cherrier J, Grulke N E, Jennings V, Pincett S, Pouyat R V, Whitlow T H, Zipperer W C. Coupling biogeochemical cycles in urban environments: ecosystem services, green solutions, and misconceptions. Frontiers in Ecology and the Environment, 2011, 9(1) : 27-36.

[62] Chang J, Wu X, Liu A Q, Xu B, Yang W, Meyerson L A, Gu B J, Peng C H, Ge Y. Assessment of net ecosystem services of plastic greenhouse vegetable cultivation in China. Ecological Economics, 2011, 70(4): 740-748.

[63] Daily G C, Matson P A. Ecosystem services: From theory to implementation. Proceedings of the National Academy of Sciences of the United States of America, 2008, 105(28) : 9455-9456. 
[64] Carpenter S R, Mooney H A, Agard J, Capistrano D, Defries R S, Diaz S, Dietz T, Duraiappah A K, Oteng-Yeboah A, Pereira H M, Perrings C, Reid W V, Sarukhan J, Scholes R J, Whyte A. Science for managing ecosystem services: Beyond the Millennium Ecosystem Assessment. Proceedings of the National Academy of Sciences of the United States of America, 2009, 106(5) : 1305- 1312.

[65] Min Y, Chang J, Ge Y, Wu X. Opportunity, challenge and countermeasure for studying relationship among multiple ecosystem services. Chinese Science Bulletin (Chinese Version), 2012, 57(22) : 2137-2142.

\section{参考文献:}

[38］葛菁, 吴楠, 高吉喜, 王晓辉, 苏德毕力格, 张晨, Ennaanay D, 田美荣. 不同土地覆被格局情景下多种生态系统服务的响应与权衡一 以雅砻江二滩水利枢纽为例. 生态学报, 2012, 32(9) : 2629-2639.

[42］张明军, 周立华. 气候变化对中国森林生态系统服务价值的影响. 干旱区资源与环境, 2004, 18(2): 40-43.

[43] 龙金金, 甄霖, 成升鬼, 鄢帮有, 马丽, 潘影, 姜鲁光, 杨莉, 曹晓晨. 98 洪水对鄱阳湖区生态系统服务的影响研究. 资源科学, 2011, 34 (2) : 220-228.

[44] 周忠学. 城市化对生态系统服务功能的影响机制探讨与实证研究. 水土保持研究, 2012, 18(5): 32-38.

[46] 肖建红, 施国庆, 毛春梅, 王敏, 邢贞相. 水坝对河流生态系统服务功能影响评价. 生态学报, 2007, 27(2): 526-537.

[47] 魏国良, 崔保山, 董世鬼, 杨志峰. 水电开发对河流生态系统服务功能的影响一以澜沧江漫湾水电工程为例. 环境科学学报, 2008, 28 (2) : 235-242.

[48］裴厦, 谢高地, 鲁春霞, 章予舒, 陈龙. 水利工程梯级开发对河流生态系统服务累积影响浅析一一以猫跳河为例. 资源科学, 2011, 33 (8) : 1469- 1474 .

[65] 闵勇, 常杰, 葛荤, 吴旭. 生态系统服务复杂关系研究的机遇, 挑战与对策. 科学通报, 2012, 57(22): 2137-2142. 


\section{ACTA ECOLOGICA SINICA Vol.33, No.19 Oct.,2013(Semimonthly) CONTENTS}

A review of ecosystem services and research perspectives

MA Fengjiao,LIU Jintong, A. Egrinya Eneji (5963)

Sexual interference in non-human primates

YANG Bin, WANG Chengliang, JI Weihong, et al (5973)

Density-dependent effect on reproduction of rodents : a review …............. HAN Qunhua, GUO Cong, ZHANG Meiwen (5981)

Proximate and ultimate determinants of food chain length ............................ WANG Yuyu, XU Jun, LEI Guangchun (5990)

Mechanism of biological control to plant diseases using arbuscular mycorrhizal fungi

LUO Qiaoyu, WANG Xiaojuan, LI Yuanyuan, et al (5997)

Advances in effects of conservation tillage on soil organic carbon and nitrogen

XUE Jianfu, ZHAO Xin, Shadrack Batsile Dikgwatlhe, et al (6006)

Habitat selection of the pre-released giant panda in Wolong Nature Reserve

ZHANG Mingchun, HUANG Yan, LI Desheng, et al (6014)

Activity rhythm and behavioral time budgets of wild Reeves's Pheasant (Syrmaticus reevesii) using infrared camera …................

ZHAO Yuze, WANG Zhichen, XU Jiliang, et al (6021)

The energy budget of tree sparrows Passer montanus in wind different speed and duration

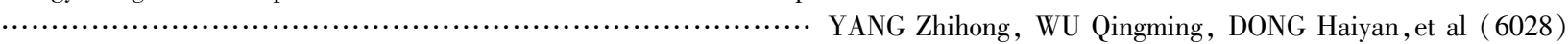

Nest site characteristics of Petaurista caniceps in Baima Snow Mountain Nature Reserve

LI Yanhong, GUAN Jinke, LI Dayong, HU Jie (6035)

Effects of habitat fragmentation on the genetic diversity of Pachycondyla luteipes on islands in the Thousand Island Lake, East

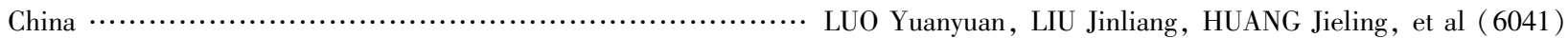

The molecular genetic relationship between the pollinators of Ficus pumila var. pumila and Ficus pumila var. awkeotsang ..............

WU Wenshan, CHEN Youling, SUN Lingli, et al (6049)

The genetic evolutionary relationships of two Eupristina species on Ficus altissima

............................................................ CHEN Youling, SUN Lingli, WU Leilei, et al (6058)

Metal uptake and root morphological changes for two varieties of Salix integra under cadmium stress

WANG Shufeng, SHI Xiang, SUN Haijing, et al (6065)

Effects of phthalic acid on seed germination, membrane lipid peroxidation and osmoregulation substance of radish seedlings ......................................................... YANG Yanjie, WANG Xiaowei, ZHAO Kang, et al (6074)

The morphological and physiological responses of Tamarix ramosissima seedling to different irrigation methods in the extremely arid area

MA Xiaodong, WANG Minghui, LI Weihong, et al (6081)

Response characteristics of photosynthetic and physiological parameters in Ziziphus jujuba var. spinosus seedling leaves to soil

water in sand habitat formed from seashells …................. WANG Rongrong, XIA Jiangbao, YANG Jihua, et al (6088)

Effects of ceramsite mulching on soil water content, photosynthetic physiological characteristics and growth of plants …...............

TAN Xuehong, GUO Xiaoping, ZHAO Tingning (6097)

Dynamics of tannin concentration and nutrient resorption for branchlets of Casuarina equisetifolia plantations at different ages .........

YE Gongfu, ZHANG Shangju, ZHANG Lihua, et al (6107)

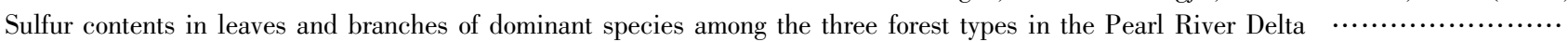

PEI Nancai, CHEN Bufeng, ZOU Zhijin, et al (6114)

Impacts of arbuscular mycorrhizal fungi and phosphorus on growth dynamics of Bauhinia faberi seedlings

SONG Chengjun, QU Laiye, MA Keming, et al (6121)

Characteristics of ion accumulation and seed germination for seeds from plants cultured at different concentrations of nitrate nitrogen and salinity

ZHOU Jiachao, FU Tingting, ZHAO Weiwei, et al (6129)

Physio-ecological effects of endophyte infection on the host grass with elevated $\mathrm{CO}_{2}$

Effects of pretreatment on germination of Typha domingensis and Phragmites australis

SHI Zhibing, ZHOU Yong, LI Xia, et al (6135)

MENG Huan, WANG Xuehong, TONG Shouzheng, et al (6142)

Transfer characteristics of cadmium from soil to Salix $\times$ aureo-pendula ….. ZHANG Wen, WEI Hong, SUN Xiaocan, et al (6147) Effect of Close-to-Nature management on the natural regeneration and species diversity in a masson pine plantation

LUO Yinghua, SUN Dongjing, LIN Jianyong, et al (6154)

Population dynamics and seed banks of the threatened seagrass Halophila beccarii in Pearl Bay, Guangxi

QIU Guanglong, FAN Hangqing, LI Zongshan, et al (6163)

Effects of biological crusts on dew deposition and evaporation in the Southern Edge of the Mu Us Sandy Land, Northern China ...... , Z

Life history characteristics and spatial distribution of Populus pruinosa population at the upper reaches of Tarim River $\cdots . . . . . . . . . . .$. .

Interactive effects of short-term nitrogen enrichment and simulated grazing on ecosystem respiration in an alpine meadow on the Tibetan Plateau ZONG Ning, SHI Peili, JIANG Jing, et al (6191) 
The correlation between soil water salinity and plant community distribution under micro-topography in Songnen Plain , W

Comparison of TSP, $\mathrm{PM}_{2.5}$ and their water-soluble ions from both inside and outside of Dafushan forest park in Guangzhou

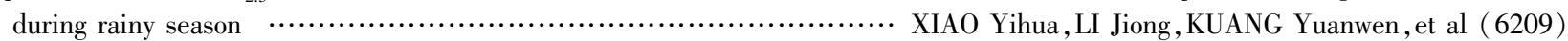

Fish community ecology in rocky reef habitat of $\mathrm{Ma}^{\prime}$ an Archipelago II . Spatio-temporal patterns of community structure

WANG Zhenhua, ZHAO Jing, WANG Kai, et al (6218)

Interannual variation in the population dynamics of snailfish Liparis tanakae in the Yellow Sea

CHEN Yunlong, SHAN Xiujuan, ZHOU Zhipeng, et al (6227)

Spatial and temporal variation of soil macro-fauna community structure in three temperate forests

... LI Na, ZHANG Xueping, ZHANG Limin (6236)

Community structure and species biodiversity of fig wasps in syconia of Ficus superba Miq. var. japonica Miq. in Fuzhou

CHEN Youling, CHEN Xiaoqian, WU Wenshan, et al (6246)

Marine ecological capital: valuation methods of marine ecosystem services …. CHEN Shang, REN Dachuan, XIA Tao, et al (6254)

Geomorphologic regionalization of China aimed at construction of nature reserve system ….......... GUO Ziliang, CUI Guofa (6264)

Impact of ecological vegetation construction on the landscape pattern of a Loess Plateau Watershed ....

YI Yang, XIN Zhongbao, QIN Yunbin, et al (6277)

Spatial heterogeneity of soil moisture across a cropland-grassland mosaic: a case study for agro-pastural transition in north of Chin

WANG Hongmei, WANG Zhongliang, WANG Kun, et al (6287)

The regional diversity of changes in growing duration of spring wheat and its correlation with climatic adaptation in Northern

China

Response of soil physical-chemical properties to rocky desertification succession in South China Karst ................................

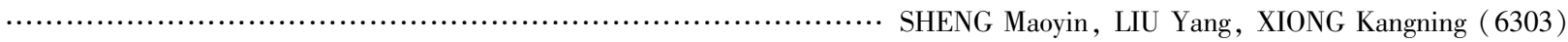

Prediction of the effects of climate change on the potential distribution of mire in Northeastern China

HE Wei, BU Rencang, LIU Hongjuan, et al (6314)

Soil nitrogen mineralization and associated temperature sensitivity of different Inner Mongolian grasslands

ZHU Jianxing, WANG Qiufeng, HE Nianpeng, et al (6320)

Effects of land use on soil nutrient in oasis-desert ecotone in the middle reach of the Heihe River

MA Zhimin, LÜ Yihe, SUN Feixiang, et al (6328)

Assessment on heavy metal pollution status in paddy soils in the northern Chengdu Plain and their potential ecological risk

QIN Yusheng, YU Hua, FENG Wenqiang, et al (6335)

Relationship between the temporal-spatial distribution of longline fishing grounds of yellowfin tuna (Thunnus albacares) and the thermocline characteristics in the Central Atlantic Ocean …......... YANG Shenglong, MA Junjie,ZHANG Yu, et al (6345)

Biological nitrogen fixation in the upper water column in the south Taiwan Strait during summer 2011

torage and drivers of forests carbon on the Beichangshan Island of Miaodao Archipelago

LIN Feng, CHEN Min, YANG Weifeng, et al (6354)

SHI Honghua, WANG Xiaoli, WANG Ai, et al (6363)

Impact of changes in vegetation types on soil $\mathrm{C}$ mineralization and associated temperature sensitivity in the Changbai Mountain

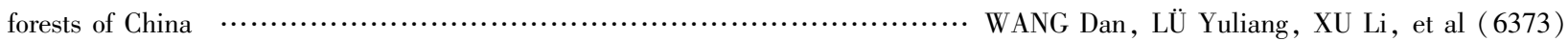

Analysis of relationship between genetic structure of Chinese Pine and mountain barriers

MENG Xiangxiang, DI Xiaoyan, WANG Mengben, et al (6382)

Soil organic carbon interpolation based on auxiliary environmental covariates:a case study at small watershed scale in Loess Hilly

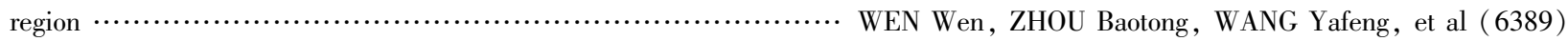

Eco-management benefit analysis of industrial resources from life cycle perspective: a case study of a virtual symbiosis network .

The game analysis between poverty and environment in ecologically fragile zones $\cdots$ QI Xinhua, YE Shilin, CHENG Yu, et al (6411)

The coupling development of economy and environment under the background of World Expo in Shanghai 


\section{《生态学报》2013 年征订启事}

《生态学报》是由中国科学技术协会主管, 中国生态学学会、中国科学院生态环境研究中心主办的生态学 高级专业学术期刊,创刊于 1981 年,报道生态学领域前沿理论和原始创新性研究成果。坚持“百花齐放,百家 争鸣” 的方针, 依靠和团结广大生态学科研工作者, 探索生态学奥秘, 为生态学基础理论研究搭建交流平台, 促进生态学研究深人发展, 为我国培养和造就生态学科研人才和知识创新服务、为国民经济建设和发展服务。

《生态学报》主要报道生态学及各分支学科的重要基础理论和应用研究的原始创新性科研成果。特别欢 迎能反映现代生态学发展方向的优秀综述性文章; 研究简报; 生态学新理论、新方法、新技术介绍; 新书评价和 学术、科研动态及开放实验室介绍等。

《生态学报》为半月刊,大 16 开本, 300 页, 国内定价 90 元/册, 全年定价 2160 元。

国内邮发代号: 82-7,国外邮发代号: M670

标准刊号:ISSN 1000-0933 CN 11-2031/Q

全国各地邮局均可订阅，也可直接与编辑部联系购买。欢迎广大科技工作者、科研单位、高等院校、图书 馆等订阅。

通讯地址: 100085 北京海淀区双清路 18 号 电话: (010)62941099; 62843362

E-mail: shengtaixuebao@ rcees.ac.cn网址: www.ecologica.cn

本期责任副主编 陈利顶 编辑部主任 孔红梅 执行编辑 刘天星 段 靖

\author{
生 态 学 报 \\ (SHENGTAI XUEBAO) \\ (半月刊 1981 年 3 月创刊)
}

第 33 卷 第 19 期 (2013 年 10 月)

\section{ACTA ECOLOGICA SINICA}

( Semimonthly, Started in 1981)

Vol. 33 No. 19 (October, 2013)

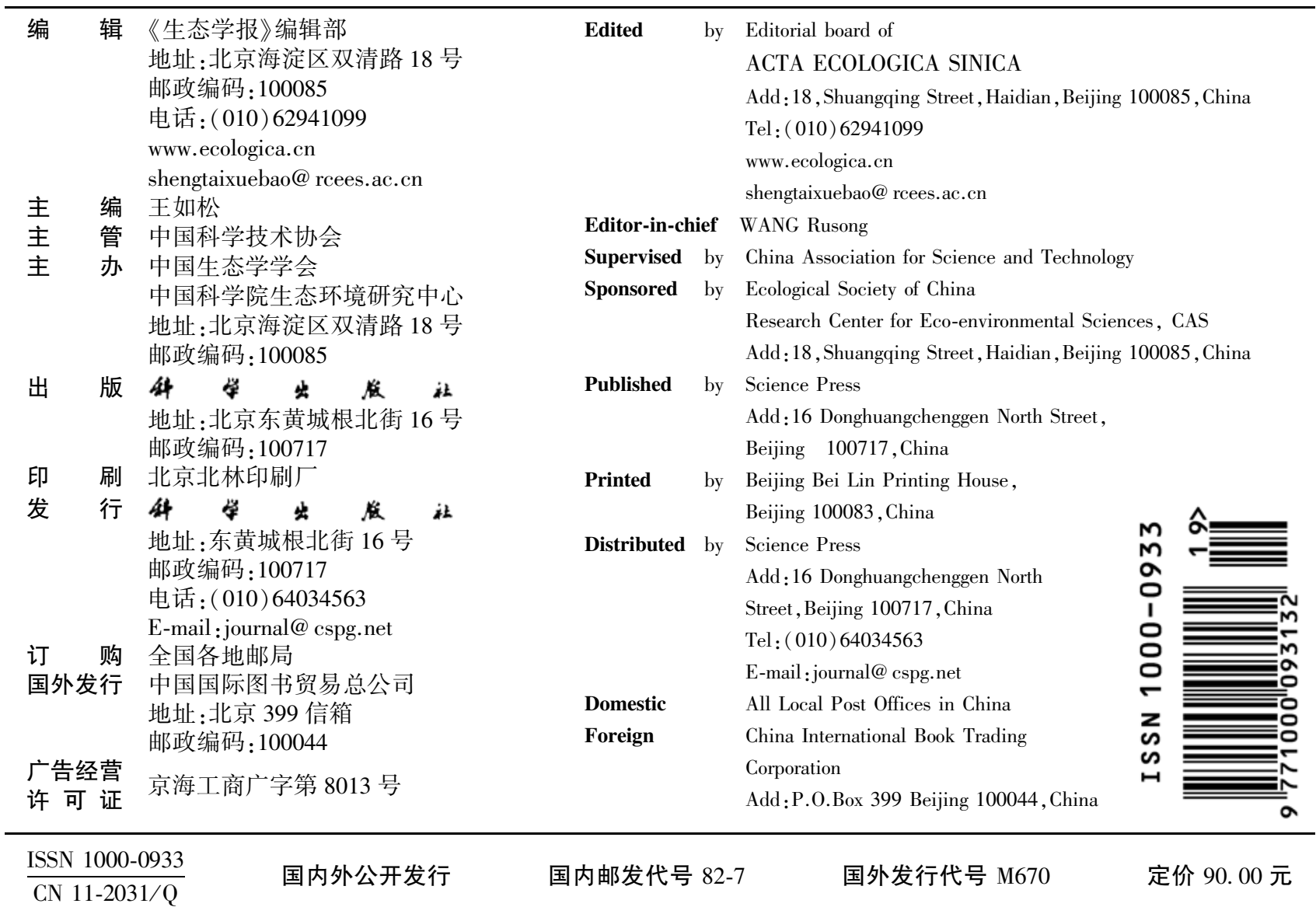

